\title{
MECP2 duplications in six patients with complex sex chromosome rearrangements
}

\author{
Amy M Breman ${ }^{1}$, Melissa B Ramocki ${ }^{2}$, Sung-Hae L Kang ${ }^{1}$, Misti Williams ${ }^{3}$, Debra Freedenberg ${ }^{4}$, \\ Ankita Patel ${ }^{1}$, Patricia I Bader ${ }^{5}$ and Sau Wai Cheung ${ }^{\star, 1}$
}

Duplications of the Xq28 chromosome region resulting in functional disomy are associated with a distinct clinical phenotype characterized by infantile hypotonia, severe developmental delay, progressive neurological impairment, absent speech, and proneness to infections. Increased expression of the dosage-sensitive MECP2 gene is considered responsible for the severe neurological impairments observed in affected individuals. Although cytogenetically visible duplications of Xq28 are well documented in the published literature, recent advances using array comparative genomic hybridization (CGH) led to the detection of an increasing number of microduplications spanning MECP2. In rare cases, duplication results from intrachromosomal rearrangement between the $X$ and $Y$ chromosomes. We report six cases with sex chromosome rearrangements involving duplication of MECP2. Cases 1-4 are unbalanced rearrangements between $\mathrm{X}$ and $\mathrm{Y}$, resulting in MECP2 duplication. The additional Xq material was translocated to $Y p$ in three cases (cases 1-3), and to the heterochromatic region of Yq12 in one case (case 4). Cases 5 and 6 were identified by array CGH to have a loss in copy number at Xp and a gain in copy number at Xq28 involving the MECP2 gene. In both cases, fluorescent in situ hybridization (FISH) analysis revealed a recombinant $\mathrm{X}$ chromosome containing the duplicated material from Xq28 on Xp, resulting from a maternal pericentric inversion. These cases add to a growing number of MECP2 duplications that have been detected by array CGH, while demonstrating the value of confirmatory chromosome and FISH studies for the localization of the duplicated material and the identification of complex rearrangements.

European Journal of Human Genetics (2011) 19, 409-415; doi:10.1038/ejhg.2010.195; published online 1 December 2010

Keywords: $M E C P 2$; array $\mathrm{CGH}$; Xq28; mental retardation

\section{INTRODUCTION}

Duplications leading to functional disomy of the gene-dense region of $\mathrm{Xq} 28$ are associated with a distinct clinical phenotype characterized by infantile hypotonia, severe developmental delay, progressive neurological impairment, susceptibility to infections, and absent speech in affected males ${ }^{1-3}$ reviewed in Sanlaville et al. ${ }^{4}$ The methyl-CpG binding protein 2 (MECP2) gene, located on $\mathrm{Xq} 28$, is thought to be the critical dosage-sensitive gene responsible for the severe phenotypes observed in these patients. MECP2 is best known for its role in Rett Syndrome (RTT, MIM 312750), a progressive neurological disorder caused by loss-of-function mutations in MECP2. ${ }^{5}$ Deletions encompassing the $M E C P 2$ gene account for approximately $11-16 \%$ of cases of Rett syndrome, without detectable point mutations. ${ }^{6,7}$ Interestingly, quantitative PCR assays, aimed at detecting MECP2 deletions in mutation-negative females, identified the first submicroscopic duplication of the entire MECP2 gene on Xq28 in a boy with features of Rett syndrome. ${ }^{1}$ It is now clear that the dosage-sensitive $M E C P 2$ gene has the capacity to cause severe clinical disease when its dosage is either depleted or enriched. More than 100 cases of Xq28 duplications encompassing MECP2 have been described to date, making this one of the most common genomic rearrangements identified in neurodevelopmentally delayed males. ${ }^{1-3,8-17}$
Genomic rearrangements leading to $M E C P 2$ duplication are nonrecurrent, and are thought to be mediated through the fork stalling and template switching (FoSTeS) mechanism. ${ }^{18}$ The reported cases in the literature vary in size and location, however the majority are intrachromosomal duplications ranging from 0.3 to $2.3 \mathrm{Mb}$ in size. Only a few reports describe cases in which the duplication is the result of another mechanism, such as rearrangements between $\mathrm{Xq}$ and $\mathrm{Xp}$, or between $\mathrm{Xq}$ and the $\mathrm{Y}$ chromosome. Here, we report six boys who have additional Xq28 chromosome material, including the MECP2 gene, resulting from either an unbalanced $\mathrm{X}-\mathrm{Y}$ translocation, or an $\mathrm{Xq}-\mathrm{Xp}$ rearrangement, resulting from a maternal pericentric inversion of the X chromosome.

\section{CASE REPORTS}

The clinical features of each patient are summarized in Table 1, and any additional available clinical information is briefly summarized in the case histories below.

\section{Case 1}

This boy was born to a $\mathrm{G}_{1} \mathrm{P}_{0-1} \mathrm{~A}_{0}$ mother at 40 weeks gestation by vaginal delivery with a birth weight of $3125 \mathrm{~g}$ (25th percentile). The pregnancy was complicated by influenza associated with dehydration.

\footnotetext{
${ }^{1}$ Medical Genetics Laboratories, Department of Molecular and Human Genetics, Baylor College of Medicine, Houston, TX, USA; ${ }^{2}$ Department of Pediatrics, Section of Pediatric Neurology and Developmental Neuroscience Baylor College of Medicine and Texas Children's Hospital, Houston TX, USA; ${ }^{3}$ Division of Genetic and Genomic Medicine, Vanderbilt University School of Medicine, Nashville, TN, USA; ${ }^{4}$ Vanderbilt University currently at Texas Department of State Health Services, Austin, TX, USA and ${ }^{5}$ Northeast Indiana Genetic Counseling Center, Fort Wayne, IN, USA

${ }^{*}$ Correspondence: Dr SW Cheung, Medical Genetics Laboratories, Department of Molecular and Human Genetics, Baylor College of Medicine, One Baylor Plaza, NAB 2015 Houston, TX 77030, USA. Tel: +1 713798 6555; Fax: +1 713798 6584; E-mail: scheung@bcm.edu
}

Received 8 March 2010; revised 13 August 2010; accepted 22 September 2010; published online 1 December 2010 


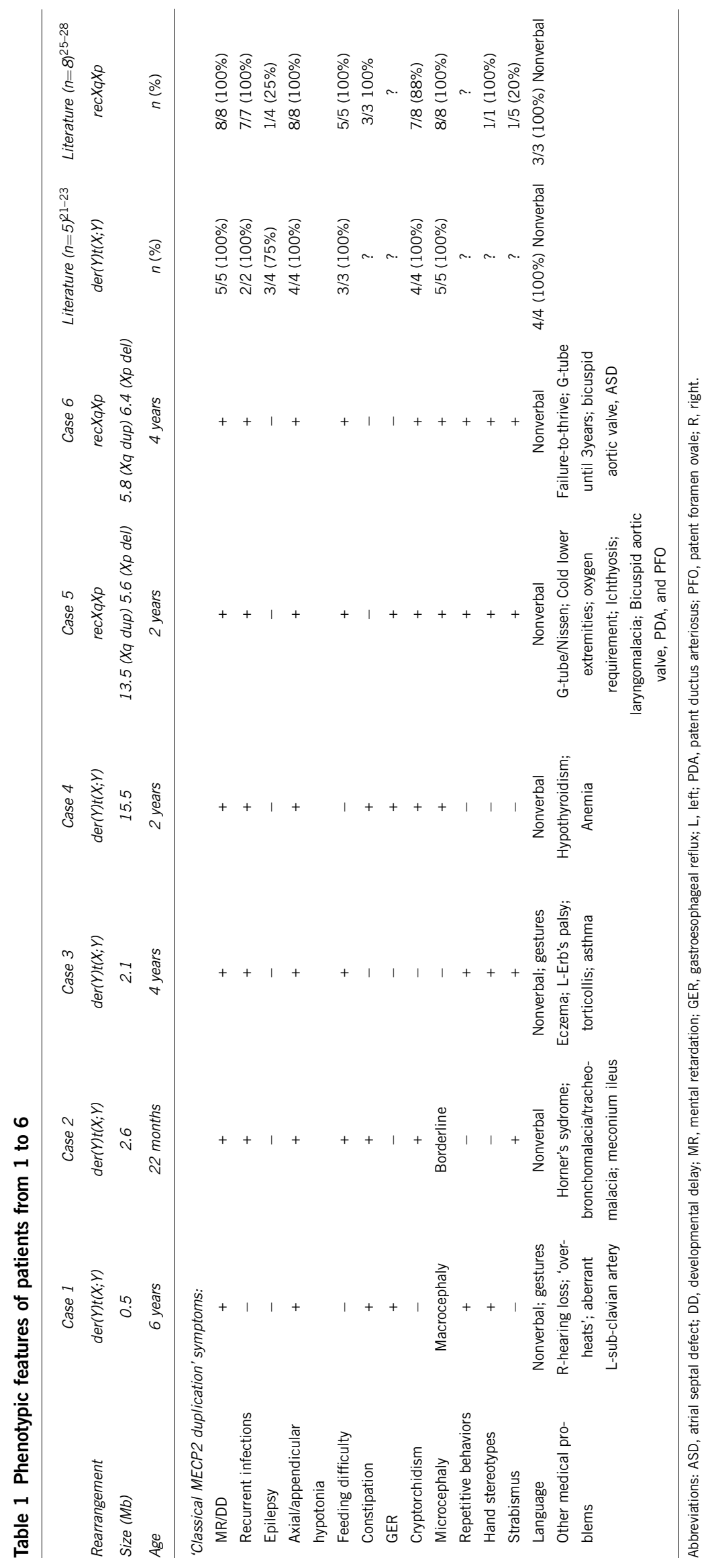


His Apgar scores were 9 at $1 \mathrm{~min}$ and 9 at $5 \mathrm{~min}$. He breast-fed well. Hypotonia and a fisted left hand were first appreciated at 3 months of age. He appears to have autonomic dysfunction as he has a high tolerance to pain (eg, crawled on a fractured arm for an entire day before the problem was recognized) and appears to 'overheat' easily, such that he appears fatigued, turns red, and has minimal diaphoresis. Magnetic resonance imaging of his brain demonstrated benign external hydrocephalus at 1 year of age and possible delayed terminal zones of myelination at 3 years of age. He required pressure equalization (PE) tube placement and adenoidectomy. Developmentally, he smiled appropriately as an infant and is a very happy child. All other developmental milestones were delayed; ambulation was achieved at $31 / 2$ years of age, and now at 6 years of age he is able to use a couple of symbols on a communication device and follow simple commands. $\mathrm{He}$ is able to point toward his needs, and he displays joint attention. He has perseverative behaviors, drooling, and bruxism; he mouths his hands and objects, chews on his clothes and blanket, and exhibits hand flapping with excitement.

\section{Case 2}

This boy was born to a 28 -year-old $\mathrm{G}_{4} \mathrm{P}_{3-4} \mathrm{~A}_{0}$ mother at 38-5/7 weeks gestation by vaginal delivery with a birth weight of $3068 \mathrm{~g}$ (20th percentile). His Apgar scores were 9 at $1 \mathrm{~min}$ and 9 at $5 \mathrm{~min}$. Hypotonia, a right Horner syndrome (no etiology identified), and left esotropia were noted during the first 3 months. He required PE tube placement. Magnetic resonance imaging of his brain at 7 months of age demonstrated hydrocephalus ex-vacuo, and a follow-up computed tomography scan of his brain documented stable prominence of the third and fourth ventricles. Facial features include brachycephaly, hypertelorism, anteverted nares, and low-set and posteriorly rotated ears. Developmentally, he does not babble, and all milestones are delayed with no ambulation achieved to date.

Case 3

This boy was born to a $\mathrm{G}_{5} \mathrm{P}_{3-4} \mathrm{~A}_{1}$ mother by Caesarian section (secondary to previous C-section and large for gestational age) at 39 weeks gestation. His birth weight was $4630 \mathrm{~g}$ (99th percentile). The pregnancy was complicated by first trimester bleeding and concern for in utero demise of a twin, a blood clot between the placenta and uterus necessitating frequent ultrasounds, and borderline gestational diabetes controlled with diet. He was hypotonic and had initial difficulty with feeding. He required PE tube placement and adenoidectomy. Other problems include bruxism, drooling, snoring with concern for obstructive sleep apnea, aspiration for thin liquids, tendency to overstuff his mouth, episodes of choking/gagging/emesis, shuddering attacks in infancy, and elevated body mass index. Developmentally, all milestones were delayed, but he ambulated independently at 24 months of age with the help of intensive physical therapy. At 3 years of age, he is generally a very happy child who babbles, uses a few words appropriately, uses a small number of signs, and claps his hands repetitively.

\section{Case 4}

This boy was born to a $\mathrm{G}_{6} \mathrm{P}_{5-6} \mathrm{~A}_{0}$ mother by induced vaginal delivery at 39-4/7 weeks gestation. His birth weight was $2670 \mathrm{~g}$ ( 7 th percentile), and Apgar scores were 7 at $1 \mathrm{~min}$ and 8 at $5 \mathrm{~min}$. The pregnancy was complicated by influenza, streptococcal pharyngitis, and exposure to hand, foot and mouth disease. He fed well at birth. Facial features at 26 months of age are shown in Figure 1a and include a flat nasal bridge, a tented and thin upper lip, and low-set ears. Other diagnoses include infantile hypotonia, benign sleep myoclonus of infancy, irondeficiency anemia, and he required PE tubes. Developmentally, all milestones are delayed and he does not yet ambulate; he now babbles at 2 years of age but does not use any words. He is a very happy and content child.

\section{Case 5}

This boy was born to a 25 -year-old $\mathrm{G}_{2} \mathrm{P}_{1} \mathrm{~A}_{0}$ mother by vaginal delivery at 37 weeks gestation. Birth weight was 2273 grams ( 3 rd percentile) and Apgar scores were 3 at $1 \mathrm{~min}$ and 9 at $5 \mathrm{~min}$. He was transferred to the NICU because of tachypnea, low glucose, and an abnormal platelet count. Notable at birth were rhizomelic shortening and dysmorphic facies, including a prominent nasal bridge, prominent nose, brachycephaly, small mouth, thin lips, high-arched palate, and a short neck with redundant skin. His ears are low set, posteriorly rotated and cup shaped, with malformed auricles and prominent antihelixes. Facial features at 2 years and 5 months of age are shown in Figure 1b. He also has a short, shield-like sternum, pectus excavatum, widely spaced nipples, a unilateral transverse palmar crease, and hypogenitalism. His hands and feet are wide and short, with mild right and left clinodactyly of short fifth fingers, mild clubfoot, and mild syndactyly. $\mathrm{He}$ has difficulty swallowing. All developmental milestones are delayed, and he does not yet ambulate. Repetitive behaviors include hand wringing.

\section{Case 6}

This boy was born to a 30 -year-old $\mathrm{G}_{2} \mathrm{P}_{1-2} \mathrm{~A}_{0}$ mother by Caesarian section at 40 weeks gestation. Birth weight was $2727 \mathrm{~g}$ (9th percentile)
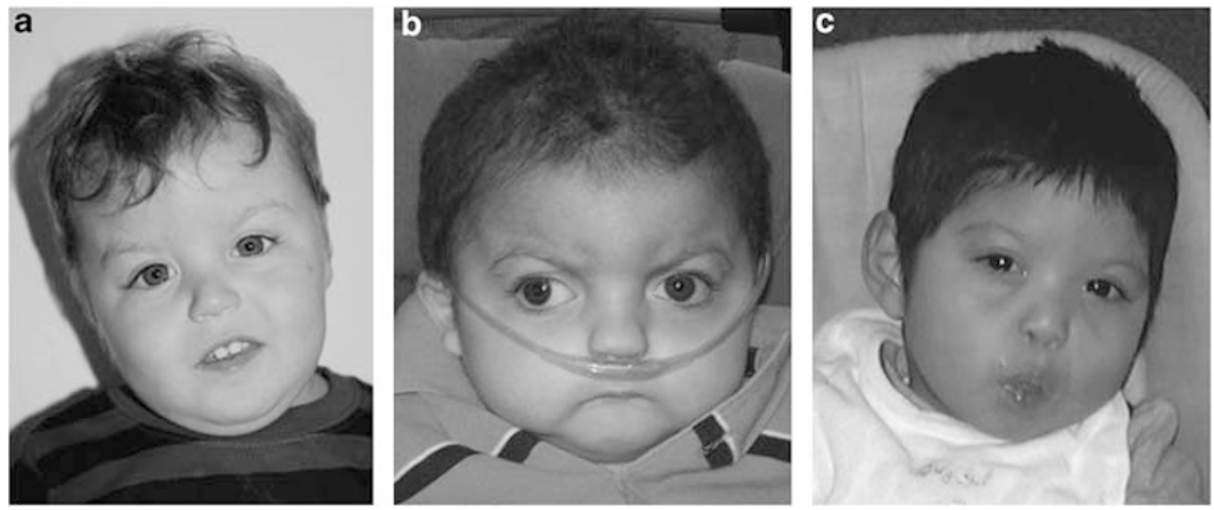

Figure 1 Facial features of case 4 (a), case 5 (b), and case 6 (c). Prominent features include small mouth, round face, short neck, low-set ears, brachycephaly, midface hypoplasia and flat nasal bridge. 
and his Apgar scores were 3 at $1 \mathrm{~min}, 6$ at $5 \mathrm{~min}$, and 8 at $10 \mathrm{~min}$. Physical exam was remarkable for hypotonia and dysmorphic features, including widely spaced eyes, hypoplastic flat nose, low-nasal bridge, flat philtrum, small jaw, high palate, small mouth, thin lips, malar hypoplasia, anterior upsweep pattern, flat face, slightly blue sclera, low-set ears with flat helix, small hands and feet, variant transverse palmar creases and hypogenitalism. Facial features at 22 months of age are shown in Figure 1c. A brain computed tomography scan was normal, and an echocardiogram showed a bicuspid aortic valve and an atrial septal defect. His mother also was found to have a bicuspid aortic valve. He required hearing-aid placement, orchiopexy, G-tube placement, adenoidectomy, and PE-tube placement. All developmental milestones are delayed, and he does not yet ambulate.

\section{MATERIALS AND METHODS}

\section{Sample collection}

Patient samples were received for clinical diagnostic testing. Informed consent approved by the institutional review board at Baylor College of Medicine was obtained for publication of photographs.

\section{Chromosomal microarray analysis}

Chromosomal microarray analysis was performed at Baylor College of Medicine Medical Genetics Labs (http://www.bcm.edu/geneticlabs/) using Affymetrix Cytogenetics Whole-Genome 2.7M Arrays (Affymetrix, Santa Clara, CA, USA). Analysis was performed according to the Cytogenetics Assay protocol provided by the supplier. Arrays were scanned using a GeneChip Scanner 3000 7G (Affymetrix) and results were analyzed using Chromosome Analysis Suite V1 software (Affymetrix).

\section{Chromosome and FISH analyses}

Standard laboratory procedures were used for metaphase preparations. GTG-banded (G-bands obtained with trypsin and Giemsa) chromosome analysis and fluorescence in situ hybridization (FISH) analysis was performed in either Medical Genetics Laboratories at Baylor College of Medicine or by the referring center.

\section{RESULTS}

For all patients in this study, the finding of MECP2 duplication was initially determined by clinical array comparative genomic hybridization (CGH) analysis. Subsequent FISH analysis led to the identification of either intrachromosomal duplications of the $\mathrm{Xq} 28$ region or translocation of the duplicated $\mathrm{Xq} 28$ region to the $\mathrm{Y}$ chromosome. This study describes a more detailed analysis of these cases, with fine mapping by high-resolution array CGH using Affymetrix $2.7 \mathrm{M}$ Cytogenetics arrays.

In Case 1, FISH analysis revealed additional Xq28 material translocated to the terminal region of $\mathrm{Yp}(\operatorname{der}(\mathrm{Y}) \mathrm{t}(\mathrm{X} ; \mathrm{Y})(\mathrm{q} 28 ; \mathrm{p} 11.3))$ (Figure 2d). Paternal FISH analysis did not show evidence of this duplication, therefore this was a de novo event. High-resolution array analysis revealed a gain in copy number on Xq28 of approximately $0.5 \mathrm{Mb}$, including MECP2, defined as arr Xq28(152638847153147516) $\times 3$ dn (Figure 2a). GTG-banded X and Y chromosomes appear normal and are shown in Figure $2 c$.

In Case 2, chromosome and FISH analyses revealed an unbalanced translocation between $\mathrm{Yp}$ and $\mathrm{Xq}$, resulting in a deletion of the pseudoautosomal region of $\mathrm{Yp}$ and a duplication of the $\mathrm{Xq} 28$ segment $(\operatorname{der}(\mathrm{Y}) \mathrm{t}(\mathrm{X} ; \mathrm{Y})(\mathrm{q} 28 ; \mathrm{p} 11.32)$ ) (Figures 2c and $\mathrm{d})$. Paternal FISH analysis revealed no evidence of a rearrangement between $\mathrm{Xq}$ and $\mathrm{Yp}$, indicating a de novo event. High-resolution array analysis revealed a gain in copy number on Xq28 of approximately $2.6 \mathrm{Mb}$, including MECP2, defined as arr Xq28(152269935-154888242)x3 dn (Figure 2a).
In Case 3, FISH analysis revealed that the duplicated Xq28 material was located at Ypter (not shown). Subsequent analysis using a highresolution array confirmed a $2.1 \mathrm{Mb}$ duplication defined as arr Xq28(152802164-154911467)x3 (Figure 2a).

In Case 4, initial array CGH analysis revealed a duplication of the region from Xq27.1 to Xq28. All probes in the unique sequences on the $\mathrm{Y}$ chromosome were present in normal copy number; however, chromosome studies later revealed that the duplicated material was present on a derivative $\mathrm{Y}$ chromosome with concomitant loss of the heterochromatic region at $\mathrm{Yq12}(\operatorname{der}(\mathrm{Y}) \mathrm{t}(\mathrm{X} ; \mathrm{Y})(\mathrm{q} 27.1 ; \mathrm{q} 12))$ (Figure 2c). High-resolution array analysis confirmed a $15.5 \mathrm{Mb}$ duplication spanning the region from Xq27.1 to Xq28, with apparent loss of the pseudoautosomal region of the $\mathrm{Y}$ chromosome, defined as arr Xq27.1q28(139334073-154911467)x3 (Figure 2a).

In Case 5, GTG-banded chromosome analysis revealed an abnormal $\mathrm{X}$ chromosome, comprised of the region from Xq26 to Xqter translocated from Xp22.2 to Xqter (Figure 2c). Consequently, the derivative $\mathrm{X}$ chromosome is deleted for the region from Xp22.2 to Xpter and duplicated for the region from Xq26 to Xqter (designated $46, Y, \operatorname{rec}(\mathrm{X}) \operatorname{inv}(\mathrm{X})(\mathrm{p} 22.2 ; \mathrm{q} 26))$. High-resolution array analysis confirmed a duplication of Xq27.2 to Xq28 spanning approximately $13.5 \mathrm{Mb}$, as well as a deletion of $\mathrm{Xp} 22.33$ to $\mathrm{Xp} 22.31$, spanning approximately $5.6 \mathrm{Mb}$ (arr Xp22.33p22.31(1-5676186)x1 mat, arr Xq27.2q28(141400011-154899855)x3 mat) (Figures 2a and b). Maternal chromosome analysis revealed an X chromosome with a pericentric inversion (Figure 2e). At the cytogenetic level, the breakpoints of the pericentric inversion are those seen in her son $(46, X, \operatorname{inv}(X)(\mathrm{p} 22.2 \mathrm{q} 26))$.

In Case 6, subtelomere FISH analysis identified a deletion of Xp and a duplication of $\mathrm{Xq}$ (Figure 2d). A subsequent chromosome analysis revealed a derivative $\mathrm{X}$ chromosome with the designation 46,Y,rec(X)inv(X)(p22.3;q28) (Figure 2c). High-resolution array analysis confirmed a duplication of Xq28 spanning approximately $5.8 \mathrm{Mb}$, and a deletion of Xp22.33 to Xp22.32 spanning approximately $6.4 \mathrm{Mb}$ (arr Xp22.33p22.32 (1-6444800)x1 mat, arr Xq28 (148964141154837233)x3 mat) (Figures $2 \mathrm{a}$ and b). Maternal chromosome analysis revealed an $\mathrm{X}$ chromosome with a pericentric inversion (report unavailable).

\section{DISCUSSION}

Duplication of the Xq28 region can occur by intrachromosomal duplication or, rarely, by complex rearrangements that result in translocation of the $\mathrm{Xq}$ segment to $\mathrm{Xp}$, to an autosome or to the $\mathrm{Y}$ chromosome. Herein, we report six cases of Xq28 duplication with $\mathrm{X}-\mathrm{Y}$ translocations or $\mathrm{Xq}-\mathrm{Xp}$ rearrangements, involving duplication of $M E C P 2$.

\section{$t(X ; Y)$ rearrangements}

Previous reports of Xq28 translocated to $\mathrm{Y}$ include Lahn et al ${ }^{19}$ who first reported the phenotype of Xq28 functional disomy in three unrelated boys with severe mental retardation, generalized hypotonia, seizures, microcephaly, and absent speech. In their report, 10 boys having an Xyq- karyotype were screened for the presence of Xq material, and the three most severely affected were found to have a derivative $\mathrm{Y}$ (designated $\mathrm{Y}_{\mathrm{Xq}}$ ) containing $\mathrm{Xq} 28$ material, resulting from an aberrant Xq-Yq exchange in the paternal germline. ${ }^{19} \mathrm{~A}$ 2005 report by Sanlaville et al ${ }^{2}$ reviews the aforementioned cases as well as two additional $\operatorname{der}(\mathrm{X}) \mathrm{t}(\mathrm{Xq} ; \mathrm{Yq})$ cases, including a de novo duplication of Xq28 translocated to Yq11.2 in a 13-month-old boy ${ }^{20}$ and a de novo duplication of the region Xq27.3-qter translocated to Yq11.2 in an 8-year-old boy. ${ }^{21}$ In all of these cases, the mechanism was 
a

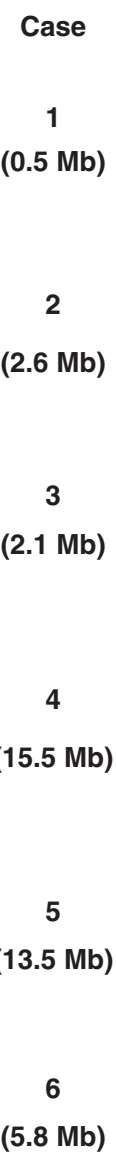

2
Xq Duplications: 138.4-154.9 Mb

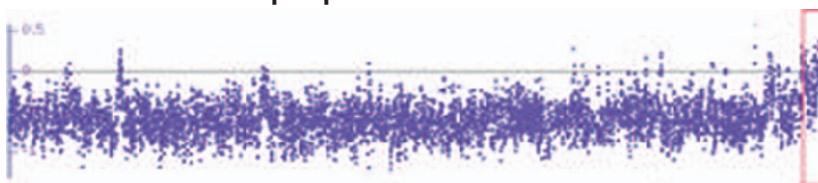

$$
=
$$

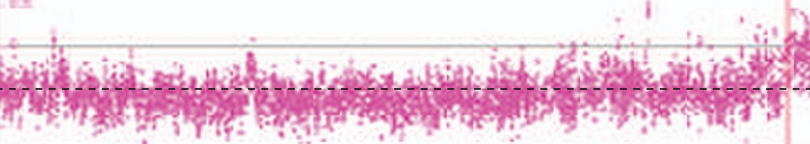
-<smiles>[CH]1CC1</smiles>

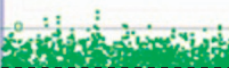
?

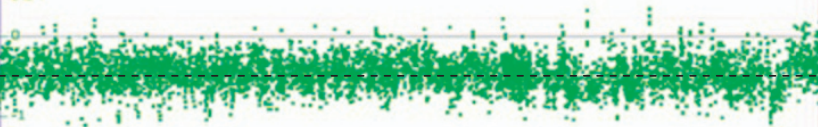

Hiscle diok tation

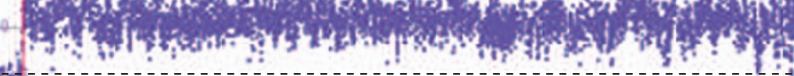

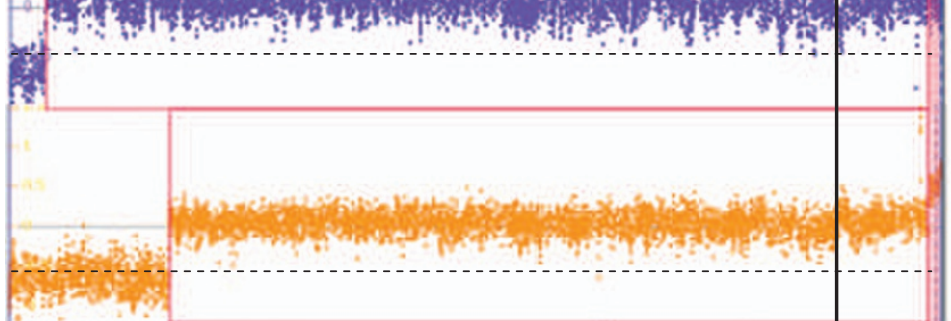

)

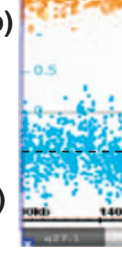

c

d

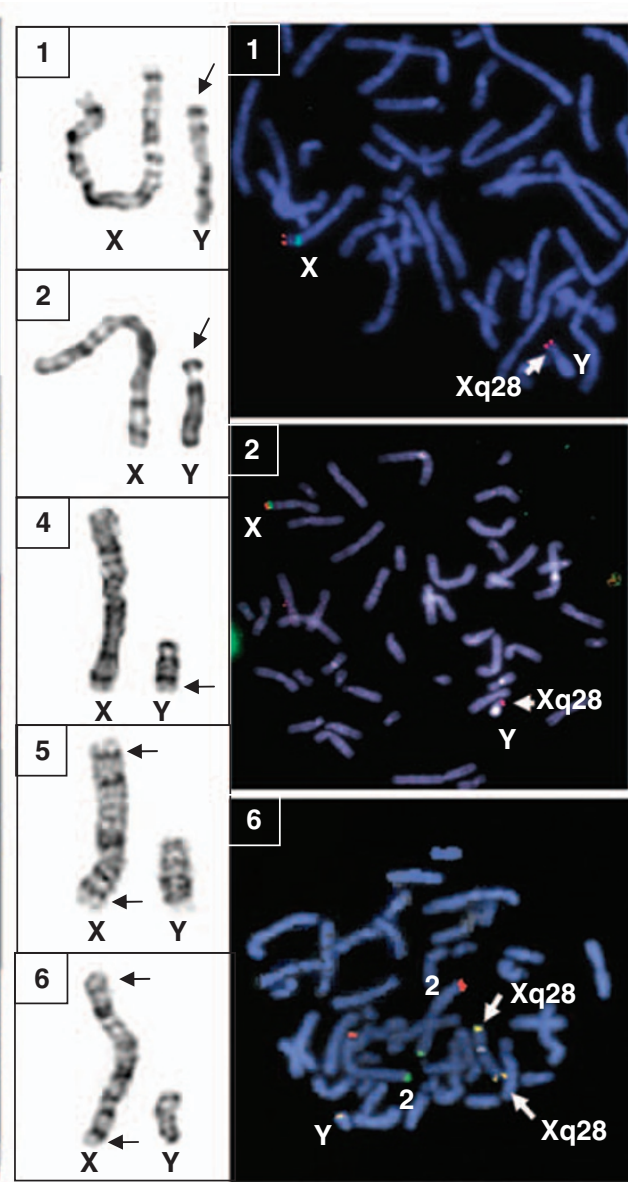

b

Case

$(5.6 \mathrm{Mb})$

6

(6.4 Mb)
Xp Deletions:1-12.8 Mb

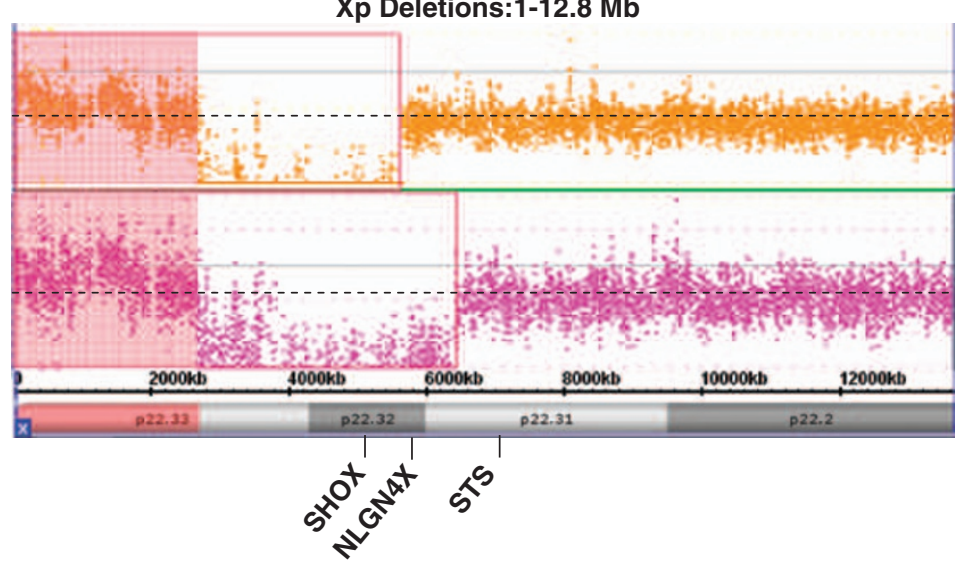

e

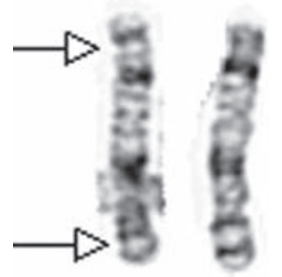

Figure 2 Cytogenetic and molecular cytogenetics analyses. Array plots for the distal Xq region (a) and distal Xp region (b) are shown for each case. The bottom horizontal bar indicates coordinates in Mb. Red boxes indicate probes that detected a gain or loss in copy number for each patient. Vertical black line indicates location of the MECP2 gene. A log2 ratio of zero indicates a copy number (CN) of two for males. In the chromosome analysis suite software, the PAR regions of $X$ are $C N=2$ in normal males (probes on the $X$ and $Y$ contribute to the signal), whereas the rest of the $X$ chromosome is $C N=1$. Copy number changes involving the PAR regions display a shift in the log2 ratio (pink highlighted regions). In case 4, the shift on Xq PAR is not observed, suggesting that the PAR on $Y q$ was lost in the $t(X q ; Y q)$ translocation. (c) GTG-banded chromosomes $X$ and $Y$ for cases $1,2,4,5$ and 6 . (d) FISH analyses for cases 1 and 2 show an Xq28 probe in red (RP11-119A22 in case 1, RP11-143H17 in case 2) hybridizing to Yp. FISH analysis for case 6 shows an Xq28 probe (yellow) hybridizing to both distal Xq and distal Xp. (e) GTG-banded X chromosomes from the mother of patient 5 . Arrows indicate the approximate breakpoints of the pericentric inversion. 
thought to be an aberrant pairing of the pseudoautosomal regions of $\mathrm{Xq}$ and $\mathrm{Yq}$ at male meiosis. In this report, we describe one case (case 4), in which the duplicated Xq28 chromosome material is translocated to the heterochromatic region of $\mathrm{Yq}$, as seen in previously reported cases (Figure 2c). ${ }^{15,20,21}$ Interestingly, our remaining three $\mathrm{t}(\mathrm{X} ; \mathrm{Y})$ cases (cases 1,2, and 3) involve translocation of the duplicated $\mathrm{X}$ chromosome material to Yp rather than to Yq. Velinov et al ${ }^{14}$ described an 8-year-old boy with a de novo duplication of approximately $2.15 \mathrm{Mb}$ of Xq28, encompassing MECP2 but not L1CAM, and translocated to distal Yp. This child presented with mental retardation, prominent ears, unstable gait and flat occiput, but notably lacked the severe hypotonia, microcephaly, and hypogonadism seen in the majority of cases with larger Xq28 duplications. In our cases 1 and 3 , the translocation of $\mathrm{Xq}$ material to Yp resulted in no detectable loss of Ypter. The deletion of Yp found in case 2, however, spanned at least $0.6 \mathrm{Mb}$ and encompassed short-stature homeobox containing gene (SHOX), which is located within the pseudoautosomal region (PAR1) of both the $\mathrm{X}$ and $\mathrm{Y}$ chromosomes. Although haploinsufficiency of SHOX is known to be associated with growth retardation, ${ }^{22}$ severe growth delay was not reported as a major clinical feature in this child.

\section{Xp-Xq rearrangements}

The literature contains only a few reports of duplication/deletion events involving terminal duplication of $\mathrm{Xq}$ and terminal deletion of $\mathrm{Xp}$. These cases are presumed to be the result of either a recombination event in a parent carrying a pericentric inversion ${ }^{23-27}$ or inherited from a phenotypically normal mother carrying the abnormal X. ${ }^{28} \mathrm{We}$ report two additional cases in which an Xq duplication encompassing MECP 2 was accompanied by an Xp deletion, resulting from a specific intrachromosomal rearrangement in which the duplicated segment of $\mathrm{Xq}$ was translocated to the $\mathrm{Xp} 22.3$ band. In each case, the derivative $\mathrm{X}$ chromosome was inherited from the mother who carried a pericentric inversion (Figure 2e). The duplicated regions in the previously reported individuals are similar to our cases, ranging from approximately 5 to $12 \mathrm{Mb}$ in size, and translocated to Xp22.3. Furthermore, many of the phenotypic features overlap with our patients, including those associated with duplication of MECP2 (ie, severe mental retardation, hypotonia, recurrent infections and dysmorphic facial features) as well as additional findings (cardiac defects, failure to thrive) that may be attributed to loss of Xpter and the large number of other genes that reside in the duplicated region of Xq (Figure 2a).

\section{Other genes involved}

Although MECP2 is thought to be the most important dosagesensitive gene that contributes to the neurological phenotypes in patients with $\mathrm{Xq} 28$ duplications, the duplications in our six patients range from $0.5 \mathrm{Mb}$ to greater than $15 \mathrm{Mb}$ and contain many genes, some of which are associated with X-linked mental retardation syndromes, including FMR1, IDS, SLC6A8, L1CAM, FLNA, GDI1, $I K B K G, D K C 1$ and $M E C P 2$ (Figure 2a). ${ }^{29}$ Furthermore, cases 5 and 6 have an additional deleted region on $\mathrm{Xp}$, a region known to contain several genes of clinical significance, including SHOX (deletions have been associated with growth retardation) and NLGN4 (mutations have been associated with autism and Asperger syndrome). Interestingly, the deleted region on Xp did not encompass the STS gene in either case 5 or case 6 , despite the fact that case 5 exhibited mild ichthyosis of his thighs. This observation could indicate a positional effect of the genomic rearrangement.

A recent report by Clayton-Smith et al ${ }^{16}$ suggested that Filamin A (FLNA; MIM:300017) gene duplication is associated with severe bowel and bladder dysfunction based on several families having either Xq28 duplication or duplication of FLNA only. Cases 1, 2, 4, 5, and 6 were noted to have constipation, however the FLNA gene was duplicated in cases 2-6, but not in case 1 . One possible explanation for this phenotype in case 1 is that duplications near but not including the FLNA gene may have an effect on FLNA gene regulation. ${ }^{30}$ Alternatively, simple constipation could be attributed to MECP2 alterations as girls with Rett syndrome also have problems with constipation. The presence of constipation in our cases may, therefore, be distinct from the severe intestinal pseudo-obstruction phenotype sometimes observed in patients with FLNA duplications and point mutations. FLNA is also known to be associated with X-linked periventricular heterotopia (OMIM 300049) as well as abnormalities of the cardiovascular system, therefore it is possible that duplication of this gene is the underlying cause of the cardiac defects observed in cases 5 and 6.

Other genes of interest include IRAK1 (duplicated in all six cases) and GDI1 (duplicated in cases 2-6). IRAK1 is involved in the innate immune response and is thought to have a role in the susceptibility to infections observed in the majority of patients with Xq28 duplications. ${ }^{10}$ Loss of function mutations in GDI1 are a known cause of $\mathrm{X}$-linked mental retardation, and it has recently been suggested that gene duplication is correlated with microcephaly. ${ }^{12}$ Notably, in case 1, the duplication does not include GDI1, and unlike the other cases this child was noted to have macrocephaly.

Although the $\mathrm{Xq}$ duplications in these six cases range in size from $0.5 \mathrm{Mb}$ to more than $15 \mathrm{Mb}$, gene inclusion in the duplicated region alone does not appear to be a sufficient explanation for the variable expressivity observed in the syndrome (Table 1). Furthermore, the young age of the boys reported herein may explain the absence of certain features that are commonly observed in patients with MECP2 duplication but generally have a later onset. For example, seizures have been reported in approximately $50 \%$ of cases of MECP 2 duplication, but were notably absent in our cases. ${ }^{4}$

Large, cytogenetically visible duplications of distal $\mathrm{Xq}$ have been described $^{31,2}$ as well as triplication of the MECP2 gene, ${ }^{8}$ which appears to increase clinical severity. Although two of the six cases reported here had duplications larger than $10 \mathrm{Mb}$ in size, the position and banding make cytogenetic detection difficult even when the resolution is high (Figure 2c). Furthermore, the majority of reported cases of Xq28 duplications involving $M E C P 2$ are less than $5 \mathrm{Mb}$ in size, and therefore would not be detectable by high-resolution chromosome analysis. Molecular methods such as multiplex ligation-dependent probe amplification can be used to confirm MECP2 duplications, but offer no information regarding the extent or genomic location of the additional material. High-resolution molecular cytogenetic methods such as FISH and array CGH analyses are complementary to each other, and in suspected cases of Xq28 duplication, they are the ideal diagnostic methods. These combined molecular assays have the capacity to identify not only duplications but also complex rearrangements such as those described herein.

\section{CONFLICT OF INTEREST}

Some of the authors are from the Department of Molecular and Human Genetics at Baylor College of Medicine, which offers extensive genetic laboratory testing, including use of arrays for genomic copy number analysis, and derives revenue from this activity.

\section{ACKNOWLEDGEMENTS}

We are grateful to the patients and their families for participation in these studies. We thank Claudia Fonseca, Patricia Crotwell, the Baylor College of Medicine Cytogenetics and Chromosome Microarray Laboratories, and the Sanford Clinic USD Cytogenetics Laboratory for their assistance with these 
cases. MBR is grateful for the support of NIH/NINDS grant 5K08NS062711-02. The content is solely the responsibility of the authors and does not necessarily represent the official views of the NINDS or the NIH.

1 Meins M, Lehmann J, Gerresheim F et al: Submicroscopic duplication in Xq28 causes increased expression of the MECP2 gene in a boy with severe mental retardation and features of Rett syndrome. J Med Genet 2005; 42: e12.

2 Sanlaville D, Prieur M, de Blois MC et al: Functional disomy of the Xq28 chromosome region. Eur J Hum Genet 2005; 13: 579-585.

3 Friez MJ, Jones JR, Clarkson $\mathrm{K}$ et al: Recurrent infections, hypotonia, and mental retardation caused by duplication of MECP2 and adjacent region in Xq28. Pediatrics 2006; 118: e1687-e1695.

4 Sanlaville D, Schluth-Bolard C, Turleau C: Distal Xq duplication and functional Xq disomy. Orphanet J Rare Dis 2009; 4: 4.

5 Amir RE, Van den Veyver IB, Wan M, Tran CQ, Francke U, Zoghbi HY: Rett syndrome is caused by mutations in X-linked MECP2, encoding methyl-CpG-binding protein 2. Nat Genet 1999; 23: 185-188.

6 Laccone F, Junemann I, Whatley S et al: Large deletions of the MECP2 gene detected by gene dosage analysis in patients with Rett syndrome. Hum Mutat 2004; 23: 234-244.

7 Van den Veyver IB, Zoghbi HY: Genetic basis of Rett syndrome. Ment Retard Dev Disabil Res Rev 2002; 8: 82-86.

8 del Gaudio D, Fang P, Scaglia F et al: Increased MECP2 gene copy number as the result of genomic duplication in neurodevelopmentally delayed males. Genet Med 2006; 8 : 784-792.

9 Froyen G, Van Esch H, Bauters M et al: Detection of genomic copy number changes in patients with idiopathic mental retardation by high-resolution X-array-CGH: important role for increased gene dosage of XLMR genes. Hum Mutat 2007; 28: 1034-1042.

10 Kirk EP, Malaty-Brevaud V, Martini N et al: The clinical variability of the MECP2 duplication syndrome: description of two families with duplications excluding L1CAM and FLNA. Clin Genet 2009; 75: 301-303.

11 Lugtenberg D, de Brouwer AP, Kleefstra T et al: Chromosomal copy number changes in patients with non-syndromic $\mathrm{X}$ linked mental retardation detected by array $\mathrm{CGH}$. J Med Genet 2006; 43: 362-370.

12 Lugtenberg D, Kleefstra T, Oudakker AR et al: Structural variation in Xq28: MECP2 duplications in $1 \%$ of patients with unexplained XLMR and in $2 \%$ of male patients with severe encephalopathy. Eur J Hum Genet 2009; 17: 444-453.

13 Van Esch H, Bauters M, Ignatius J et al: Duplication of the MECP2 region is a frequent cause of severe mental retardation and progressive neurological symptoms in males. Am J Hum Genet 2005; 77: 442-453.

14 Velinov M, Novelli A, Gu $\mathrm{H}$ et al: De-novo $2.15 \mathrm{Mb}$ terminal Xq duplication involving MECP2 but not L1CAM gene in a male patient with mental retardation. Clin Dysmorphol 2009; 18: 9-12.
15 Smyk M, Obersztyn E, Nowakowska B et al: Different-sized duplications of Xq28, including MECP2, in three males with mental retardation, absent or delayed speech, and recurrent infections. Am J Med Genet B Neuropsychiatr Genet 2008; 147B: 799-806

16 Clayton-Smith J, Walters S, Hobson E et al: Xq28 duplication presenting with intestinal and bladder dysfunction and a distinctive facial appearance. Eur J Hum Genet 2009; 17: 434-443.

17 Prescott TE, Rodningen OK, Bjornstad A, Stray-Pedersen A: Two brothers with a microduplication including the MECP2 gene: rapid head growth in infancy and resolution of susceptibility to infection. Clin Dysmorphol 2009; 18: 78-82.

18 Carvalho CM, Zhang F, Liu P et al: Complex rearrangements in patients with duplications of MECP2 can occur by fork stalling and template switching. Hum Mol Genet 2009; 18: 2188-2203.

19 Lahn BT, Ma N, Breg WR, Stratton R, Surti U, Page DC: Xq-Yq interchange resulting in supernormal $X$-linked gene expression in severely retarded males with 46,XYq- karyotype. Nat Genet 1994; 8: 243-250.

20 Teek R ZR, Zõrjanova T, Tammur P, Bartsch O: Case report: boy with severe hypotonia, hypogenitalism, chronic interstitial pneumonie, and partial $X$ disomy, karyotype $46, X$, $\operatorname{der}(\mathrm{Y}) \mathrm{t}(\mathrm{X} ; \mathrm{Y})(\mathrm{q} 28 ; \mathrm{q} 11.2)$. Eur J Hum Genet 2004; 12: 129

21 Novelli A, Bernardini L, Salpietro DC et al: Disomy of distal Xq in males: case report and overview. Am J Med Genet A 2004; 128A: 165-169.

22 Borie $\mathrm{C}$, Leger J, Dupuy $\mathrm{O}$ et al: Translocation $(\mathrm{Y} ; 22)$ resulting in the loss of SHOX and isolated short stature. Am J Med Genet A 2004; 125A: 186-190.

23 Mohandas T, Geller RL, Yen PH et al: Cytogenetic and molecular studies on a recombinant human $X$ chromosome: implications for the spreading of $X$ chromosome inactivation. Proc Natl Acad Sci USA 1987; 84: 4954-4958.

24 Schmidt M, Du Sart D, Kalitsis P et al: Duplications of the X chromosome in males: evidence that most parts of the $X$ chromosome can be active in two copies. Hum Genet 1991; 86: 519-521.

25 Vasquez Al, Rivera $\mathrm{H}$, Bobadilla L, Crolla JA: A familial Xp+ chromosome, dup (Xq26.3—>qter). J Med Genet 1995; 32: 891-893.

26 Lammer EJ, Punglia DR, Fuchs AE, Rowe AG, Cotter PD: Inherited duplication of Xq27.2- > qter: phenocopy of infantile Prader-Willi syndrome. Clin Dysmorphol 2001; 10: 141-144.

27 Kokalj-Vokac N, Marcun-Varda N, Zagorac A et al: Subterminal deletion/duplication event in an affected male due to maternal $X$ chromosome pericentric inversion. Eur $J$ Pediatr 2004; 163: 658-663.

28 Goodman BK, Shaffer LG, Rutberg J et al: Inherited duplication Xq27-qter at Xp22.3 in severely affected males: molecular cytogenetic evaluation and clinical description in three unrelated families. Am J Med Genet 1998; 80: 377-384.

29 Ropers HH: X-linked mental retardation: many genes for a complex disorder. Curr Opin Genet Dev 2006; 16: 260-269.

30 Ramocki MB, Tavyev YJ, Peters SU: The MECP2 duplication syndrome. Am J Med Genet 2010; 152A: 1079-1088.

31 Lachlan KL, Collinson MN, Sandford RO, van Zyl B, Jacobs PA, Thomas NS: Functional disomy resulting from duplications of distal Xq in four unrelated patients. Hum Genet 2004; 115: 399-408. 